\title{
Comparison of the Apparent Mass during Exposure to Whole-Body Vertical Vibration between Japanese Subjects and ISO 5982 Standard
}

\author{
Setsuo MAEDA ${ }^{1 *}$ and Neil J. MANSFIELD ${ }^{2}$ \\ ${ }^{1}$ Department of Human Engineering, National Institute of Industrial Health, 21-1 Nagao 6-Chome, Tama-Ku, \\ Kawasaki 214-8585, Japan \\ ${ }^{2}$ Department of Human Sciences, Loughborough University, Loughborough, Leicestershire, LE11 3TU, UK
}

Received March 6, 2005 and accepted May 2, 2005

\begin{abstract}
Objective: The purpose of this study was to investigate the apparent mass of the sitting human body and to compare it with current experimental data and the ISO 5982 standard impedance model. Method: The apparent mass of the seated human body in the vertical direction was measured. Twelve male subjects were exposed to random whole-body vibration of frequency range $(1-20 \mathrm{~Hz})$, with a vibration excitation level of $1.0 \mathrm{~m} / \mathrm{s}^{2} \mathrm{r}$.m.s. The body posture was upright with no backrest contact. Results: The obtained apparent masses were compared to the International Standard, (ISO 5982). The biodynamic response of the seated Japanese subjects peaked in the 4-6.5 $\mathbf{~ H z}$ frequency range, which is little bit higher than the reported range of fundamental frequencies (4.5$5 \mathrm{~Hz}$ ) in most other studies which used different experimental conditions. The outcomes show a clear difference between apparent mass of Japanese subjects and ISO 5982 data. Conclusion: It is not sufficient to apply the ISO 5982 standard to Japanese vehicle design or dummy design.
\end{abstract}

Key word: Apparent Mass, ISO 5982, Whole-body vibration, Seated subject

\section{Introduction}

For a rigid structure, the apparent mass is equal to the weight. However, if the structure has some compliance, such as the human body, the apparent mass provides a measure of the frequencies where the structure resonates. The apparent mass method is one method of measuring the dynamic response of the human body ${ }^{1,2}$. Also, the apparent mass of the human body has been used as a tool to enable prediction of the dynamics of vehicle seats, to provide target dynamic response characteristics for the design of seat vibration test dummies, and for the further understanding of fundamental biomechanical responses of people ${ }^{3-17}$. Many studies in the literature have reported apparent masses of seated human subjects based on experiments carried out in

*To whom correspondence should be addressed. laboratories at many different geographical locations.

The International Standard, ISO 5982 ${ }^{18}$, was published in 2002. This International Standard incorporates the most recent data published on driving-point mechanical impedance and/or apparent mass and seat-to-head transmissibility. In the ISO 5982 standard, rules for selection of source data are defined and are shown in Table 1. Most published studies complying with these rules are based on European or North American populations.

There are no studies that have compared the apparent mass of Japanese subjects with the ISO 5982 data. Therefore, it is not clear whether the ISO 5982 apparent mass data can be used in the design of Japanese vehicles and dynamic dummies.

The main objective of this study was to measure the apparent mass data for Japanese subject. In addition, we also compared the findings of apparent mass with the ISO 
Table 1. Selected rules of the apparent mass of the ISO 5982 standard

\begin{tabular}{ll}
\hline $\begin{array}{l}\text { Body Mass }(\mathrm{Kg}) \\
\begin{array}{l}\text { Subject's feet condition } \\
\text { Type of vibration }\end{array}\end{array}$ & $\begin{array}{l}\text { Mean body mass of the test subject population; } 52.7 \mathrm{~kg} \text { to } 87.2 \mathrm{~kg} \text { range } \\
\text { Data sets acquired under vibration excitation r.m.s. unweighted amplitudes below } 5 \mathrm{~m} / \mathrm{s}^{2}, \\
\text { with the nature of the excitation specified as being either sinusoidal or broad-band random. }\end{array}$ \\
Frequency range & $\begin{array}{l}\text { Data sets acquired under vibration excitations including spectral components within the } 0.5 \\
\text { Hz to } 20 \mathrm{~Hz} \text { frequency range. }\end{array}$ \\
Vibration direction & $\begin{array}{l}\text { Data sets acquired under vibration excitations constrained to the vertical direction. } \\
\text { Subject population }\end{array}$ \\
Subject posture & $\begin{array}{l}\text { Data sets acquired with subject population clearly identified. Single subject populations. } \\
\text { Data sets reporting the subject posture as being seated erect without backrest support, }\end{array}$ \\
\hline
\end{tabular}

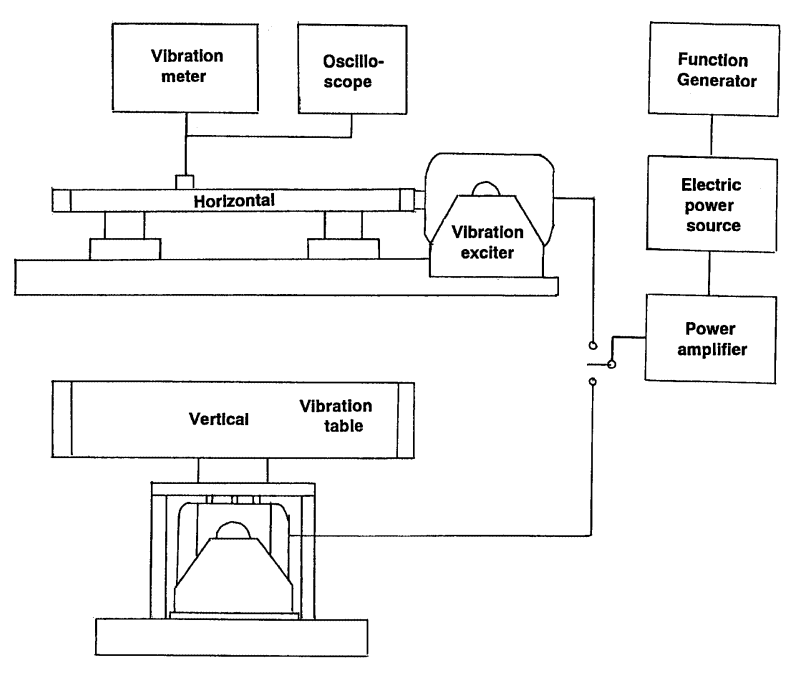

Fig. 1. Experimental apparatus of this study.

5982 data. The findings of this study regarding healthy Japanese subjects' apparent mass data will be provided when the ISO 5982 standard is revised.

\section{Method}

\section{Subjects}

Twelve Japanese male subjects participated in the experiment. The subjects had a mean age of $27.9 \mathrm{yr}$ (s.d. 8.6), a mean weight of $65.8 \mathrm{~kg}$ (s.d. 11.6) and a mean stature of $171 \mathrm{~cm}$ (s.d. 11.6). Each subject was exposed to a vibration stimulus. None of the subjects had any low-back pain at the time of the experiments. The apparent mass data of the ISO 5982 standard is provided for the weight range of 52.7 to $87.2 \mathrm{~kg}$, but, the ISO 5982 standard does not mention the age and height of the subjects, therefore, age and height data might influence the measurement results of the apparent mass.

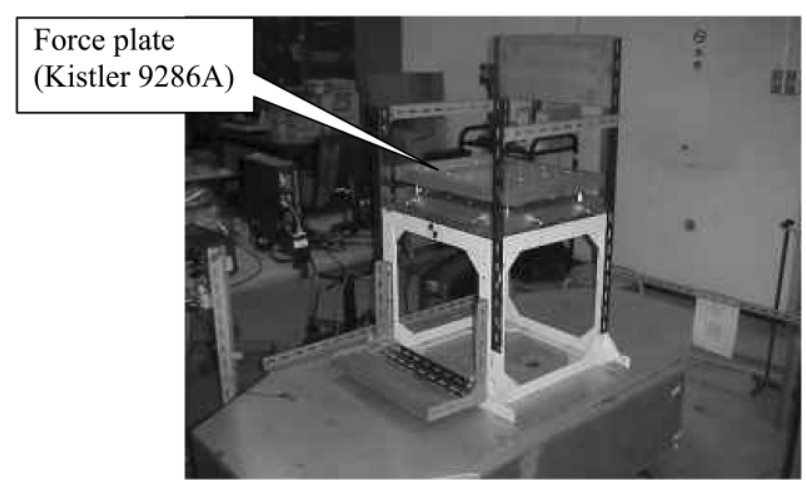

Fig. 2. Rigid seat with a Kistler 9286A force plate was mounted on the aluminium vibration table.

\section{Experimental apparatus}

A vertical electro-hydraulic vibrator with low distortion was used to generate the vibration stimuli. This system had a peak-to-peak stroke of $100 \mathrm{~mm}$ and is in the laboratories of the National Institute of Industrial Health, Kawasaki, Japan. The experimental apparatus used in the present study is shown in Fig. 1.

Whole-body vibration was produced by an electro-dynamic vibration exciter powered by a $440 \mathrm{~kg}$ vibration power force (ASE-385LW; Akashi Co. Japan). An aluminium vibration table, $1,800 \mathrm{~mm}$ by $900 \mathrm{~mm}$ and $304 \mathrm{~mm}$ thick, was attached to the vibrator to provide a surface which vibrated vertically. This plate has a honeycomb structure to reduce its weight, $90 \mathrm{~kg}$ for the vertical vibration table. And the rigid seat with a Kistler 9286A force plate was mounted on the aluminium vibration table as shown in Fig. 2.

Background vibration of the vibrator table was less than $3 \times 10^{-3} \mathrm{~m} / \mathrm{s}^{2}$ r.m.s. at a frequency of $50 \mathrm{~Hz}$. The acoustic noise level at the position of the subject's head was $50 \mathrm{~dB}$ (A). 


\section{Experimental procedure}

Before the experiment, the purpose of the study was explained to all the subjects who gave their consent for participation. They were free to withdraw at any time although no subject chose to withdraw. The experiment was approved by the Research Ethics Committee of the National Institute of Industrial Health. The vibration stimulus was a random vertical signal equalised so that equal energy was generated at frequencies from 1 to $20 \mathrm{~Hz}$. This signal had a magnitude of $1.0 \mathrm{~m} / \mathrm{s}^{2}$ r.m.s. (un-weighted) and a duration of $60 \mathrm{~s}$. The magnitude of $1.0 \mathrm{~m} / \mathrm{s}^{2}$ r.m.s. was selected as this has been used in almost of all studies of vertical apparent mass as shown in Table A.1 of Annex A of the ISO 5982 standard. The force at the seat was measured using a Kistler 9286A force plate. Acceleration was measured using a Brüel and Kjær 4370 accelerometer. The influence of the mass of the force plate was removed using a mass cancellation technique. The vibrator was controlled by, and force and acceleration signals were acquired by, an HVLab data acquisition system. Data was acquired via anti-aliasing filters at 512 samples per second via anti-aliasing filters set at $170 \mathrm{~Hz}$.

\section{Apparent mass determination}

The apparent mass is usually defined as:

$$
M(f)=\frac{F(f)}{a(f)}
$$

where $M(f)$ is the apparent mass, $F(f)$ is the force and $a(f)$ is the acceleration at frequency $f$. Force and acceleration are measured at the seat-person interface.

In the frequency domain, the apparent masses can be calculated using the cross spectral density (CSD) method defined by:

$$
H(f)=\frac{G_{i o}(f)}{G_{i i}(f)}
$$

where $G_{i o}(f)$ is the cross spectral density between the acceleration and the force, and $G_{i i}(f)$ is the power spectral density of the acceleration. Mass cancellation was applied to subtract the 'No-load apparent mass' (mass of the seat surface) from the measured apparent mass. Transfer functions were calculated with a resolution of $0.5 \mathrm{~Hz}$.

\section{Results and Discussion}

Figure 3 illustrates the individual vertical apparent mass responses of the 12 subjects seated on the force plate under
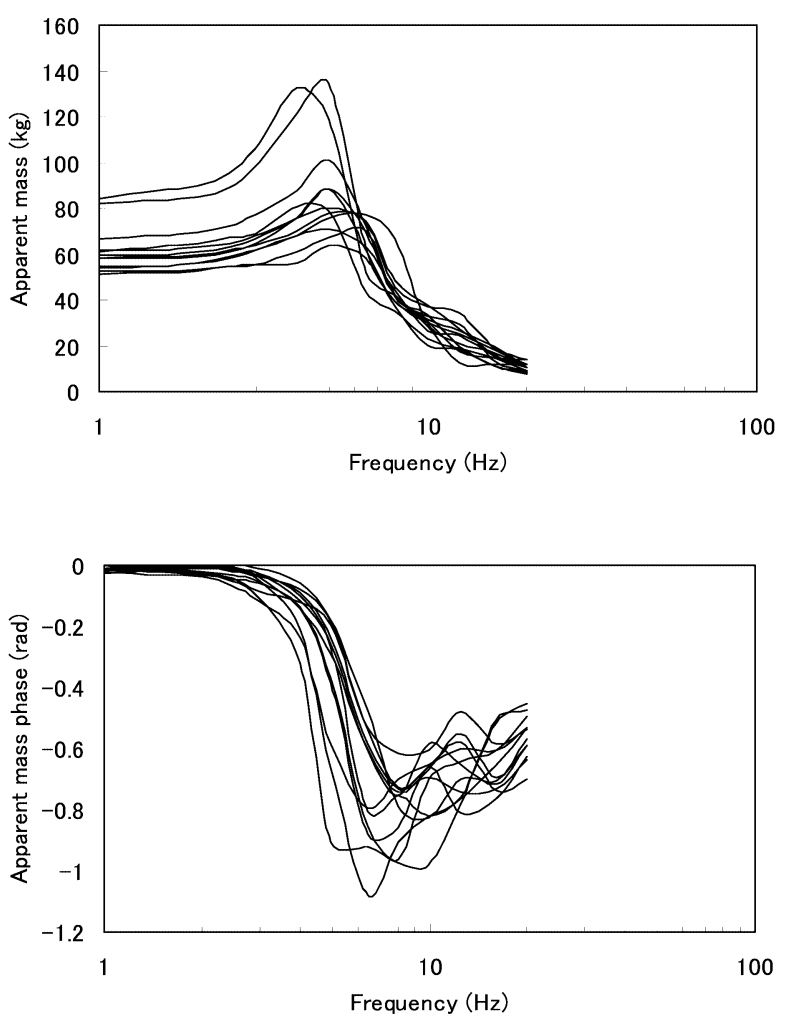

Fig. 3. Modulus and phase of apparent masses of 12 male subjects measured using random vibration.

vertical random vibration of $1.0 \mathrm{~m} / \mathrm{s}^{2}$ r.m.s. acceleration magnitude. The results show considerable scatter in the magnitude and phase responses. This scatter in magnitude, however, diminishes at frequencies above $15 \mathrm{~Hz}$, while the corresponding scatter in the phase responses increases.

The resonance frequencies ranged between 4.0 and 6.5 $\mathrm{Hz}$. The median resonance frequency was $5.2 \mathrm{~Hz}$. The magnitude at resonance ranged from $65 \mathrm{~kg}$ to $140 \mathrm{~kg}$.

Peaks in the normalized apparent mass ranged from 1.28 to 1.67 . The mean normalized resonance magnitude was 1.4 as shown in Fig. 4.

Although the values are similar to those published in the literature for studies using different subjects and different equipment, the biodynamic response of the seated Japanese subjects peaked in the $4-6.5 \mathrm{~Hz}$ frequency range, which is little bit higher than the reported range of fundamental frequencies $(4.5-5 \mathrm{~Hz})$ in most other studies involving different experimental conditions. The phase also corresponded to the responses previously reported. The modulus of the apparent masses measured using random stimuli was similar to one another.

The results of apparent mass of Japanese subjects are compared with ISO 5982 in Fig. 5. The peak apparent mass 


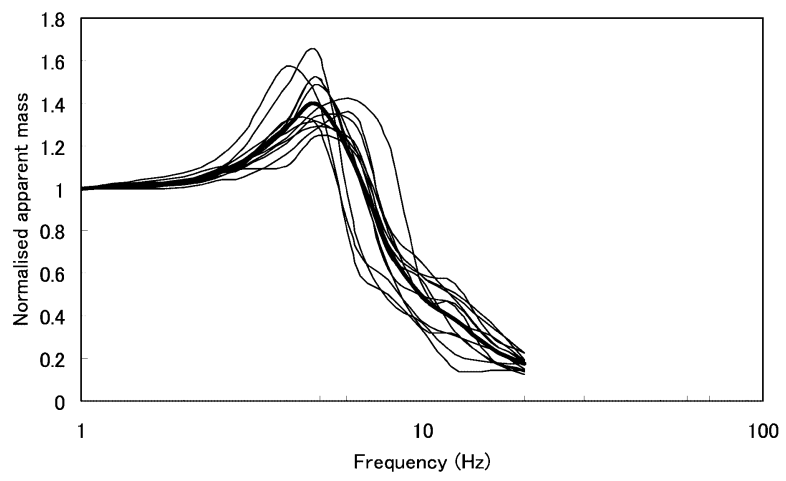

Fig. 4. Normalized apparent masses of 12 subjects.

magnitude of the upper limit obtained in this experiment is considerably higher than ISO 5982 standard values of the upper limit.

From Fig. 5, it is also clear that the mean values of the apparent mass of the ISO 5982 are different from the mean values of the current experimental apparent mass data. Furthermore, it is clear there is a different tendency at the phase of apparent mass. These differences might be dependent on the subjects' age or height. From these results, the values of ISO 5982 should not be applied to the design of Japanese vehicles or dynamic dummies directly.

\section{Conclusions}

In this experiment, apparent masses of 12 Japanese subjects were measured using random stimuli in the frequency range $1-20 \mathrm{~Hz}$ and unweighted acceleration of $1.0 \mathrm{~m} / \mathrm{s}^{2} \mathrm{r}$.m.s. Although apparent masses were generally similar to those in the literature, it is clear that the apparent mass of ISO 5982 is different from the current experimental data. Application of the apparent mass data in standard ISO 5982 should therefore only be carried out with caution in the design of Japanese vehicles and dynamic dummies. Further research is required on the relationship between the anthropometric parameters and the biodynamics of the subjects in order to improve the ISO 5982 standard.

\section{Acknowledgements}

The authors acknowledge the assistance of staff and students at Tokyo Metropolitan University. Their help is greatly appreciated.
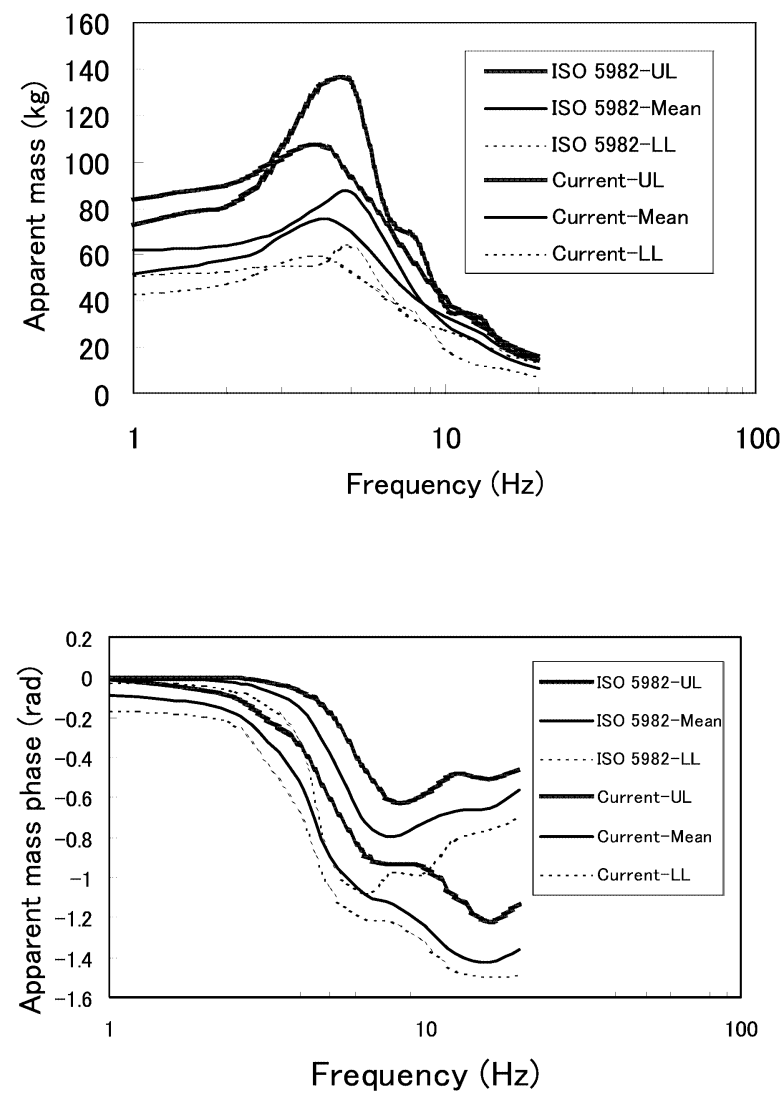

Fig. 5. Current results and ISO 5982 data of means, lower limits, and upper limits for the apparent mass.

\section{References}

1) Mansfield NJ (2004) Human response to vibration. CRC Press, Boca Rotan.

2) Griffin MJ (1990) Handbook of human vibration. Academic Press, London.

3) Fairley TE, Griffin MJ (1983) Application of mechanical impedance methods to seat transmissibility. In: Proceedings of International Conference on Noise Control Engineering. 533-6, Edinburgh.

4) Fairley TE, Griffin MJ (1989) The apparent mass of the seated human body: Vertical vibration. J Biomech 22, 81-94.

5) Hinz B, Seidel H (1987) The nonlinearity of the human body's dynamic response during sinusoidal whole body vibration. Ind Health 25, 169-81.

6) Wu X (1998) Study of driver-seat interactions and enhancement of vehicular ride vibration environment. $\mathrm{PhD}$ Thesis, Concordia University, Montreal.

7) Boileau P-E, Rakheja S, Wu X (2002) A body mass dependent mechanical impedance model for 
applications in vibration seat testing. J Sound Vib 253, 243-64.

8) Wei L, Griffin MJ (1998) The prediction of seat transmissibility from measures of seat impedance. $\mathrm{J}$ Sound Vib 214, 121-37.

9) Lewis CH, Griffin MJ (2002) Evaluating the vibration isolation of soft seat cushions using an active anthropodynamic dummy. J Sound Vib 253, 295-311.

10) Mansfield NJ, Griffin MJ (2002) Effects of posture and vibration magnitude on apparent mass and pelvis rotation during exposure to whole-body vertical vibration. J Sound Vib 253, 93-107.

11) Mansfield NJ, Griffin MJ (2000) Non-linearities in apparent mass and transmissibility during exposure to whole-body vertical vibration. J Biomechan 33, 93341.

12) Rakheja S, Haru I, Boileau P-E (2002) Seated occupant apparent mass characteristics under automotive postures and vertical vibration. J Sound Vib 253, 57-75.
13) Holmlund P, Lundström R (1998) Mechanical impedance of the human body in the horizontal direction. J Sound Vib 215, 801-12.

14) Holmlund P, Lundström R, Lindberg L (2000) Mechanical impedance of the human body in vertical direction. Appl Ergonomics 31, 415-22.

15) Holmlund P, Lundström R (2001) Mechanical impedance of the sitting human body in single-axis compared to multi-axis whole-body vibration exposure. Clin Biomech 16, S101-10.

16) Gurram R, Rakheja S, Gouw GJ (1995) Mechanical impedance of the human hand-arm system subject to sinusoidal and stochastic excitations. Int $\mathrm{J}$ Ind Ergonomics 16, 135-45.

17) International Organization for Standardization (2002) Mechanical vibration and shock-Range of idealized values to characterize seated-body biodynamic response under vertical vibration. ISO 5982. ISO, Geneva. 